\title{
2075 Papillary muscles and trabeculations significantly impact ventricular volume, ejection fraction, and regurgitation assessment by cardiovascular magnetic resonance in patients with hypertrophic cardiomyopathy
}

\author{
Yuchi Han*1, Eric Olson ${ }^{1}$, Martin S Maron², Warren J Manning1 and \\ Susan B Yeon ${ }^{1}$
}

Address: ${ }^{1}$ BIDMC, Boston, MA, USA and ${ }^{2}$ Tufts New England Medical Center, Boston, MA, USA

* Corresponding author

from I th Annual SCMR Scientific Sessions

Los Angeles, CA, USA. I-3 February 2008

Published: 22 October 2008

Journal of Cardiovascular Magnetic Resonance 2008, I0(Suppl I):A344 doi:I0.I I86/I532-429X-I0-SI-A344

This abstract is available from: http://jcmr-online.com/content/I0/SI/A344

(c) 2008 Han et al; licensee BioMed Central Ltd.

\begin{abstract}
Introduction
Measurement of valvular regurgitation is important in patients with hypertrophic cardiomyopathy (HCM). Using a cardiovascular magnetic resonance (CMR) manual partition method that includes papillary muscles and trabeculations as part of the ventricular cavity volume combined with phase velocity methods, the regurgitant fraction correlates well with assessment by Doppler echocardiography in patients with normal wall thickness. However, inclusion of papillary muscles and trabeculations as components of left ventricular (LV) mass may provide more accurate results. The impact of papillary muscle and trabeculation partitioning may be particularly prominent among patients with HCM for whom inclusion of these structures in the ventricular cavity volume may result in an overestimation of ventricular volumes and quantified valvular regurgitation.
\end{abstract}

\section{Methods}

A total of $30 \mathrm{HCM}$ patients (17 males, age $40.2 \pm 16.8$ years) were imaged with CMR from 2005 to 2007. Qualitative mitral and tricuspid regurgitation data from Doppler echocardiography were obtained from echocardiography reports. Endocardial LV and RV borders were manually traced at end-diastole and at end-systole on short axis stack images using the CMR analysis package on Philips View Forum (release 4). Papillary muscles and prominent trabeculations were included as part of LV cavity volume in Method 1 and excluded in Method 2. LV and RV EDV and end-systolic volume (ESV) were determined using a modified Simpson's rule summation of disks method. Stroke volume $(\mathrm{SV})=\mathrm{EDV}-\mathrm{ESV}$, and ejection fraction $(E F)=S V / E D V$. Aortic and pulmonic forward volumes were calculated from phase velocity data (1). Regurgitant volume (RegV) was calculated as the difference between the LVSV or RVSV and the forward aortic or pulmonic flow volume, respectively. Regurgitant fraction $(\mathrm{RF})=\mathrm{RegV} / \mathrm{SV}$. The mitral or tricuspid regurgitant score (MRS or TRS) was then obtained by classifying RF into mild, moderate, moderate to severe, or severe categories and the difference between CMR and Doppler assessments (0 to 4) were recorded for each contouring method and compared using Wilcoxon signed rank test.

\section{Results}

There were significant differences between Methods 1 and 2 (all $\mathrm{p}<0.0001$ except when specified) for LV mass and volumetric measurements. The LV mass index was $99.2 \pm$ $34.3 \mathrm{~g} / \mathrm{m} 2$ vs. $114.1 \pm 41.4 \mathrm{~g} / \mathrm{m} 2$, LVEDV was $160.2 \pm 44.1$ $\mathrm{ml}$ vs. $131.1 \pm 34.4 \mathrm{ml}$, LVSV was $106 \pm 28.3 \mathrm{ml}$ vs. $98.4 \pm$ $26.8 \mathrm{ml}$, LVEF was $66.9 \pm 7.3 \%$ vs. $75.4 \pm 8.8 \%$, RVEDV was $143.4 \pm 39.5 \mathrm{ml}$ vs. $128.7 \pm 34.7 \mathrm{ml}$, RVSV was $96.7 \pm$ $24.5 \mathrm{ml}$ vs. $89.8 \pm 21.1 \mathrm{ml}(\mathrm{p}=0.0027)$, and RVEF was $68.1 \pm 7.4 \%$ vs. $70.6 \pm 7.6 \%$. For MRS and TRS, the results 
are shown in median with interquartile ranges. For MRS, it was $2[1,2]$ vs. $1[0,2](\mathrm{p}=0.0038)$. For TRS, it was $1[1$, 2] vs. $1[0,1](\mathrm{p}=0.0175)$.

\section{Conclusion}

In patients with HCM, significant difference exists in the result of volumetric measurements with the inclusion or exclusion of papillary muscles and trabeculations. Excluding the papillary muscles and trabeculations in volumetric measurements yielded MR and TR grades that correlated better with Doppler findings compared to standard analysis techniques. Therefore, these data suggest that in HCM patients, routine contouring methods should exclude the papillary muscles and trabeculations from ventricular volumes in order to provide a more accurate assessment of ventricular mass, volumes, and atrioventricular valvular regurgitation.

Publish with Biomed Central and every scientist can read your work free of charge

"BioMed Central will be the most significant development for disseminating the results of biomedical research in our lifetime. " Sir Paul Nurse, Cancer Research UK

Your research papers will be:

- available free of charge to the entire biomedical community

- peer reviewed and published immediately upon acceptance

- cited in PubMed and archived on PubMed Central

- yours - you keep the copyright

Submit your manuscript here:

http://www.biomedcentral.com/info/publishing_adv.asp 